\title{
A EXPERIÊNCIA PARTICIPATIVA NO AMAPÁ: ANÁLISE DO PLANO DIRETOR DE LARANJAL DO JARI
}

\author{
Luana Vieira ${ }^{1}$ \\ Victoria Reis ${ }^{2}$ \\ Jose Alberto Tostes ${ }^{3}$
}

\begin{abstract}
RESUMO
Nas últimas décadas a participação popular tem sido vista como fator fundamental para o planejamento urbano, partindo do pressuposto da ineficácia dos planos diretores tecnocráticos utilizados no Brasil. A partir da constituição de 1988 um outro paradigma foi inaugurado no Brasil com o conceito da participação em foco. O objetivo deste era democratizar o processo de planejamento nos municípios, e foi expresso claramente em 2001 através do Estatuto da Cidade. Neste cenário, o artigo tem como objetivo traçar o perfil da participação no município amapaense de Laranjal do Jari. Para isso, foram analisados o Plano Diretor Participativo (PDP) de Laranjal do Jari e as referências bibliográficas existentes sobre os PDPs no estado do Amapá.
\end{abstract}

PALAVRAS-CHAVE: Plano Diretor, Participação, Planejamento Urbano, Laranjal do Jari, Amapá

\section{THE PARTICIPATORY EXPERIENCE IN AMAPÁ: PLAN DIRECTOR OF LARANJAL DO JARI ANALYSIS}

\begin{abstract}
In recent decades the participation has been seen as a key factor for urban planning, based on the assumption of ineffectiveness of the technocratic master plans used in Brazil. From the 1988 constitution another paradigm was opened in Brazil with the participation concept in focus. The objective was to democratize the process of urban planning in municipalities, and was clearly expressed in 2001 by the Estatuto da Cidade (City Statute). In this scenario, the article aims to outline the profile of participation in the Amapás municipe Laranjal do Jari. For reaching this objective, we analyzed the Participatory Master Plan (PMP) of Laranjal do Jari and references of PMPs in the state of Amapá.
\end{abstract}

KEY WORDS: Master Plan, Participation, Urban Planning, Laranjal do Jari, Amapá.

\footnotetext{
${ }^{1}$ Acadêmica de Arquitetura e Urbanismo, Universidade Federal do Amapá. luanavieira.arq@gmail.com

${ }_{2}^{2}$ Acadêmica de Arquitetura e Urbanismo, Universidade Federal do Amapá. victoriareis14@gmail.com

${ }^{3}$ Pós-Doutor em Arquitetura e Urbanismo, Universidade Federal do Amapá. tostes.j@gmail.com
} 


\section{LA EXPERIENCIA PARTICIPATIVA EN AMAPÁ: ANÁLISIS DEL PLAN MAESTRO DE LARANJAL DO JARI}

\section{RESUMEN}

En las últimas décadas la participación ha sido visto como un factor clave para la planificación urbana, basada en la ineficacia de la asunción de los Planes Maestros tecnocráticos utilizados en Brasil. Desde la Constitución de 1988 otro paradigma se inauguró en Brasil con el enfoque del concepto de participación. El objetivo de este era democratizar el proceso de planificación en los municipios, y se expresó claramente en 2001 por el Estatuto de la Ciudad. En este escenario, el artículo pretende esbozar el perfil de la participación en el municipio de Amapá Laranjal do Jari. Para ello, se analizó el Plan Director Participativo (PDP) de Laranjal do Jari y las referencias existentes en el PDP en el estado de Amapá.

PALABRAS CLAVE: Plan Maestro, Participación, Planificación Urbana, Laranjal do Jari, Amapá.

\section{INTRODUÇÃO}

Para a elaboração deste artigo foi realizada a análise do perfil da participação em Laranjal do Jari, através da leitura da bibliografia existente sobre o município. Como fundamento teórico houve uma busca relacionada ao planejamento urbano e à participação, baseado no plano diretor realizado para o município no ano de 2005 e em definições pertinentes à classificação de tal metodologia. Estas podem ajudar no entendimento de determinados fenômenos ocorridos durante o processo participativo.

O município estudado é localizado no estado do Amapá, região norte brasileira e, sendo parte da Amazônia, apresenta vasta cobertura vegetal: 93,54\% de seu território é protegida por unidades de conservação e reservas indígenas, segundo Tostes (2009). Sua população desenvolveu-se a partir da favela fluvial conhecida como Vila do Beiradão, tendo seu núcleo iniciado especialmente pelo fluxo migratório que a empresa Jari Celulose manteve ao se instalar na região. 
Assim como nos demais estados brasileiros, no Amapá por décadas vigorou o modelo de plano diretor tecnocrático, sendo experimentado pela sua capital, Macapá, de 1959 a 2003, como observado por Tostes (2006). Durante muito tempo, os únicos municípios do estado a ter plano diretor definido foram Macapá e Santana, os atuais núcleos urbanos, sendo que a adoção da metodologia participativa data o ano de 2004.

Laranjal do Jari, apesar do crescimento exponencial de sua população pela atividade da Jari Celulose, não contou com o auxílio de um plano diretor no seu desenvolvimento, nem mesmo uma legislação especifica para o uso do solo e edificações até 2005, segundo Tostes. A dificuldade encontrada pela equipe da UNIFAP em reunir dados sobre o município para a elaboração do plano, apontado por Tostes, demonstrou a origem da ineficácia e estagnação da tentativa de planejamento pelo poder público. Se, segundo Faccio (2006), a ação do planejamento urbano tem sido um instrumento de poder e obtenção de privilégio, Laranjal do Jari é um exemplo das calamidades provocadas por tal gestão centralizadora.

\section{A NECESSIDADE DE UM PLANO DIRETOR PARTICIPATIVO}

O ponto de partida da busca pelo desenvolvimento urbano do munícipio de Laranjal do Jari se dá em função das características e necessidades apresentadas pela população. O histórico de omissão e marginalização sofrido pela população laranjalense iniciado pela falta de infraestrutura no recebimento da empresa Jari Celulose, é o ponto chave para entender o contexto no qual o município é inserido e assim compreender a importância da participação social na concepção do plano diretor de tal região.

A historicidade do município é demonstrativa da causa de suas deficiências na gestão e organização pública. Com a instalação de empreendimentos, houve uma grande demanda de mão de obra sem que fosse implantada a infraestrutura necessária para receber os trabalhadores. Em consequência disso, Laranjal do Jari 


\section{Revista Nacional de}

Gerenciamento de Cidades

apresenta graves patologias de cunho socioambiental, entre elas a falta de saneamento básico, segundo Tostes (2009).

Em um município o qual cresceu desordenadamente $e$ alheio as necessidades de seus cidadãos, a participação é uma ferramenta indispensável para a adequada elaboração e gestão do plano diretor. O elemento participativo foi tomado como embasamento para as ações decorrentes ao planejamento urbano do município através da realização de oficinas, seminários, audiências públicas e de questionários.

As pesquisas realizadas in loco pela equipe de profissionais, foram um marco para o município, bem como os eventos informativos. Através disso, a conscientização local do direito democrático a participação no planejamento urbano, bem como a necessidade de integração desse processo para se ter objetivos coletivos, foram esclarecidas como metas dos PDPs, segundo Tostes (2009).

Tal iniciativa também tem um elevado grau de importância para a conscientização quanto os direitos e deveres de cada um dos atores sociais, pelo que é apresentado pelo Governo Do Estado Do Amapá-1999.

É claro que precisamos cobrar do Estado que ele exerça completamente o seu papel. Falta-nos, apenas, descobrir que fazemos o melhor dos lobbys quando cumprimos o nosso. Não se dispensa as formas tradicionais de pressão. Elas, no entanto, não garantiram, em quase quinhentos anos, qualquer significativo avanço no campo do bem-estar popular e da justiça distributiva, critérios hodiernos para considerarmos. (GEA, 2009)

\section{A PARTICIPAÇÃO SOCIAL}

A Metodologia Participativa foi inserida para democratizar as questões do planejamento urbano, ou seja gerar um envolvimento maior da comunidade nas discussões que se formam em torno das questões sociais, políticas, econômicas e administrativas que são vividas por essa sociedade. Procura-se com essas metodologias tentar aproximar os cidadãos do conhecimento de seu papel na sociedade, fazendo com que o mesmo atue diretamente nessa construção, 
Revista Nacional de

Gerenciamento de Cidades

mostrando suas necessidades e seus anseios. Tostes (2005) enumera algumas metodologias de participação popular, tais como Seminários, Oficinas de Capacitação, Encontros, Audiências Públicas e Assembleias, exemplos de eventos realizados pelo grupo responsável pela elaboração do PDP de Laranjal do Jari. (TOSTES, 2005).

De acordo com o contexto apresentado para a participação em do Jari, fezse uma análise de três metodologias de segmentação desenvolvidas por diferentes autores. Parte das características presentes no processo participativo ocorrido nesse município podem ser definidas por estas classificações.

A classificação da participação realizada por Nogueira (2004) apud Toni (2009) é dividida em quatro grandes modalidades, a primeira delas é a assistencialistas considerada também filantrópica e solidária. São reveladas frequentemente em cenários com características adversas como estratégia de sobrevivência e com um grau mínimo de consciência política, visa atender demandas imediatas; cenário muito característico da área de estudo.

A participação corporativa está voltada para os interesses de um segmento ou categoria social específica, geralmente motivada por lutas econômicas também pode ser considerada pré-política. Pela baixa organização dos grupos/ comunidades laranjalense e pela preponderância dos interesses individuais ou de pequenos grupos se torna uma classificação compatível à realidade local.

A modalidade de participação eleitoral engloba tanto os direitos civis do cidadão na sua relação com o estado quanto os direitos políticos. No entanto esta possui limitações pelas distorções das preferências pessoais, falhas no processo eleitoral e déficit no controle dos eleitos, entraves encontrados os quais influenciaram na efetividade do Plano Diretor.

A participação política está diretamente relacionada ao estado e é identificada como manifestação de poder político. Alimentada pela participação corporativa e eleitoral e pela essência do debate político democrático ou gestão coletiva dos conflitos, questiona e formula novos consensos sociais e formaliza 
Revista Nacional de

Gerenciamento de Cidades

conquistas de direitos universais. Este é estágio mais avançado de participação e que ainda não foi alcançado, mesmo depois da aprovação do PDP.

Ricci (2004) apud Toni (2009) considera uma tipologia de três estágios no contexto de participação local: a fase de legitimação, na qual se conquista a legitimidade no interior dos governos, o reconhecimento e a incorporação dos ritos participativos, reconhecimento externo da capacidade mobilizatória e representatividade de conselheiros e delegados.

No segundo estágio - a efetividade; as pautas de legitimação junto ao governo e a sociedade são unificadas. Há ampliação e criação de programas e agendas intersetoriais, 0 debate do planejamento, empoderamento das organizações sociais em redes e descentralização de políticas e serviços.

A terceira fase é a de institucionalização com a inserção de estruturas de gestão, monitoramento e avaliação das ações de governo, internalizando formas, instrumentos e processos participativos. Este seria um nível ideal de democracia a ser atingido, porém ainda encontra-se em fase de construção tanto a nível regional quanto nacional.

Bava (2002) apud Tostes (2005) define um conceito de gestão descentralizada onde há a participação popular direta no modo de gestão, descentralização administrativa e decisória; funcionalismo público e planejamento junto com os cidadãos. Também nesse contexto a metodologia participativa visa à atuação efetiva com o conhecimento dos participantes, superando a distância entre o governo e seus cidadãos no planejamento urbano.

Segundo a análise do autor, o atendimento ao coletivo pode ser obtido através de negociações, acordos voluntários, partilha de custo entre os membros do grupo e organização dos objetivos a serem alcançados. Foi baseado nessa premissa que os eventos para a construção do Plano foram realizados. (TOSTES, 2005).

A classificação para os atores de tal participação são divididos entre atores sociais (igreja, cooperativas, associações, movimento estudantil, representantes de 
movimentos sociais, lideranças comunitárias, iniciativa privada e sindicatos) e atores do poder público (poder executivo, poder legislativo, prefeitura, universidade). (TOSTES, 2005)

\section{O PERFIL DA PARTICIPAÇÃO LARANJALENSE}

Tostes (2005) analisa a lógica da ação coletiva em Laranjal do Jari pela perspectiva de que não é pautada em interesses coletivos, fato agravador da problemática urbana e que foi percebido durante a concepção do Plano Diretor da região. No município em questão, os atores estão representados por ONGs as quais realizam reivindicações pontuais ligadas aos aspectos políticos partidários de natureza social, econômica e ambiental pelo poder público municipal o qual tem a função de administrar as necessidades coletivas.

Exemplificando os atores sociais, Tostes (2005) cita as comunidades laranjalenses, e as classifica como ativas (destacando a forte pressão social sofridas pelas lideranças para defesa dos interesses coletivos) participantes efetivas do processo de discussão das políticas públicas da cidade, incluindo a realização de eventos públicos.

Todavia, há uma contradição entre esse fato e a situação anterior e posterior à aprovação do Plano Diretor no que diz respeito ao real envolvimento social nas causas urbanísticas; consequência da má organização dos grupos nos aspectos ideológicos e infraestruturais. Por tanto a participação em Laranjal do Jari não pode ser classificada na modalidade política, como também não se enquadra na fase de institucionalização, citadas anteriormente.

Apesar das comunidades/instituições não terem financiamento próprio, algumas possuem vinculação partidária ou "apadrinhamento" político, fato que gera descrédito desses grupos perante a sociedade com relação à sua atuação e interesses. É comum por parte de grupos/movimentos, não só em Laranjal do Jari como em todo Amapá, a utilização da própria organização social para manipulação 
política, fato que torna o município "um grande loteamento político partidário". (TOSTES, 2005)

A Universidade Federal do Amapá (UNIFAP), como instituição de maior credibilidade na região, teve forte atuação no processo de mobilização e auxílio na conciliação de interesses dos variados grupos da sociedade laranjalense para a confecção do Plano Diretor. Fato que se deve à implantação de um polo da UNIFAP em Laranjal do Jari, gerando formação de recursos humanos e desenvolvimento de pesquisas referentes ao desenvolvimento regional aplicados ao estado; aproximando as relações populares com a universidade na medida em que esta atua também na melhoria da qualidade de vida da população.

Analisando os atores sociais pelo prisma da iniciativa privada, tem-se a empresa Jari Celulose a principal modificadora e influenciadora no desenho urbano do município. Primeiramente, pelo papel desencadeador do processo de formação da aglomeração às margens do rio Jari, conhecida como Beiradão, na década de 70 . Apesar das expectativas entorno da mesma contribuir com investimentos no campo social e na melhoria da qualidade de vida, não há vislumbres de tais benefícios para a população.

A empresa Jari Celulose ainda influencia diretamente na esfera econômica do município, através do núcleo de trabalhadores concentrados no distrito de Monte Dourado, território paraense separado de Laranjal do Jari pelo Rio Jari. Outro ponto de influência seriam os empregos indiretos em Laranjal do Jari gerados pela empresa e a destinação de recursos através da Fundação ORSA na ordem de grandeza de $1 \%$ do valor bruto para investimentos locais, os quais na opinião grande parte da população são meras estratégias de marketing e não de preocupação social, como tal projeto sugere. (TOSTES, 2005)

Tostes (2009) enfatiza que a metodologia utilizada no plano diretor de Laranjal do Jari vai além de um mero cumprimento às exigências do Estatuto da Cidade. A proposta era de fazer uma integração da sociedade e do poder público, como primeiro passo para a eficiência do planejamento, levando em consideração o 


\section{Revista Nacional de}

conhecimento dos moradores a respeito da área, costumes e experiências. Ou seja, o cunho participativo do plano funcionaria com o consenso de ideias entre a sociedade e o governo.

O trabalho de pôr em prática o lado participativo do plano visou o envolvimento dos cidadãos nas questões políticas, ambientais, econômicas e administrativas do município. Segundo Tostes (2009), esse debate seria organizado em seminários, oficinas de capacitação, encontros, audiências públicas, assembleias, questionários, realizados no espaço público.

Houve a firmação de um convenio com a Universidade Federal do Amapá de cooperação técnico-científica, ajudando principalmente no caráter participativo do plano. Foi a partir desse convênio que as pesquisas sobre a cidade e a formação de indicadores com base em pesquisas de campo foram sendo esquematizados. $O$ mapeamento cartográfico, fotográfico e bibliográfico, que encontrava-se insuficiente ou defasado, foi atualizado até o panorama da cidade se fazer claro para dar continuidade ao desenvolvimento do plano.

As oficinas foram inicialmente voltadas apenas para técnicos, lideranças comunitárias e entidades participativas. Na primeira houve a elaboração de propostas preliminares, as quais podem ser constatadas no plano diretor pelas orientações e princípios norteadores do Ministério das Cidades (2004). Já a segunda incluiu a participação de segmentos sociais, estudantes secundaristas e membros da comunidade em geral com a apresentação do primeiro documentário sobre Laranjal do Jari.

Um ponto importante a respeito da forma que funcionou a participação foi a aplicação de questionários para formulação de indicadores de moradia. A partir do levantamento dos dados apresentados abaixo como um demonstrativo das problemáticas encontradas no município, com a representação de um fator de cada área pesquisada durante esta fase. 


\section{Revista Nacional de}

Gerenciamento de Cidades

Tabela 01 - Informações da população local recolhidas

\begin{tabular}{|l|c|}
\hline \multicolumn{1}{|c|}{ Dados coletados } & Média geral no município \\
\hline Procedência do indivíduo (naturalidade laranjalensse) & $18 \%$ dos habitantes \\
\hline Tempo de residência no município (mais de 16 anos) & $48 \%$ dos habitantes \\
\hline $\begin{array}{l}\text { Condições de habitabilidade (paredes de madeira) } \\
\text { encanada) }\end{array}$ & $62,01 \%$ das habitações \\
\hline Renda familiar (de R $\$ 176,00$ à R $\$ 350,00)$ & $92 \%$ das habitações \\
\hline Nível de escolaridade (no ensino fundamental) & $27,8 \%$ das famílias \\
\hline $\begin{array}{l}\text { Participação em programas sociais (Programa Luz para Viver } \\
\text { melhor) }\end{array}$ & \begin{tabular}{l} 
Mais de $20 \%$ da amostra \\
\hline $\begin{array}{l}\text { Portadores de necessidades especiais (problemas físicos) } \\
\text { Acesso a serviços básicos (esgoto: fossa séptica) }\end{array}$
\end{tabular} \\
\hline $\begin{array}{l}\text { Principais problemas que exigem solução imediata } \\
\text { (saneamento) }\end{array}$ & $37 \%$ das habitações \\
\hline
\end{tabular}

Fonte: Tostes (2009), adaptado pelas autoras.

A audiência pública do Plano Diretor de Laranjal do Jari tinha como objetivo a aprovação da proposta do Plano Direto Participativo, contando com a participação de instituições municipais, acadêmicos, entidades representativas locais e comunitários em geral. $O$ interesse pela resolução dos problemas e organização em comum entre o governo municipal, universidade, entidades e a comunidade resultou em uma parceria de tais atores sociais.

Após essa análise, foram escolhidos os temas prioritários a permearem o plano, tornando-o objetivo. Os principais problemas abordados foram saneamento básico, saúde, educação, opções de lazer, segurança pública, mobilidade, habitação. Foi realizada a apresentação do plano e do vídeo do Ministério das Cidades, de modo a desfazer a resistência que a maioria dos munícipes apresentou, devido ao descrédito com relação ao poder público, segundo Tostes (2009). 
A culminância da participação popular, segundo Tostes (2009), deu-se na Audiência Pública, onde houve a apresentação e aprovação da proposta do Plano Diretor. Contou com a participação de mais de vinte segmentos sociais, totalizando 525 participantes registrados, entre autoridades municipais e estaduais, representantes da sociedade civil organizada, acadêmicos, comunitários da zona urbana e rural, instituições municipais, estaduais e federais, técnicos da UNIFAP e técnicas da Caixa Econômica Federal

Segundo o Ministério das Cidades, o mapeamento da evolução histórica da cidade, dos indicadores diversos, da caracterização dos bairros, do uso do solo, infraestrutura urbana é uma etapa fundamental, bem como confrontar essas leituras técnicas com a comunitária. A acessibilidade desses mapas aos participantes e municípios em geral deverá ser cumprida, de modo a esclarecer os estudos (MINISTÉRIO DAS CIDADES, 2004).

\section{CONSIDERAÇÕES FINAIS}

Há um consenso relacionado à notoriedade da participação de todos os atores sociais no planejamento urbano que tende a adquirir uma visibilidade ainda maior, atuando como peça chave a possibilitar a efetividade do desenvolvimento sustentável nos munícipios. A experiência de Laranjal do Jari como coletora de dados possibilita o fornecimento de informações para o melhor entendimento de fenômenos urbanos ocorridos no município.

Depois de 9 anos de aprovação do PDP de Laranjal do Jari, a reflexão feita é de que o processo participativo não deve parar na concepção do plano de diretrizes urbanas, precisa ir além. A criação de comitês de bairro ou de interesses direcionados de forma a mobilizar cada cidadão a fiscalizar o plano do qual participou é imprescindível. A comodidade e falta de crédito no cumprimento de leis, internalizados pela população, é a grande lacuna no processo de aplicabilidade do 


\section{Revista Nacional de}

plano diretor, que só pode ser preenchida com o monitoramento ativo da população organizada.

É certo que as autoridades públicas têm suas obrigações para com as problemáticas e questões presentes no meio urbano, no entanto é indispensável a compreensão da necessidade de participação da sociedade civil em todo o processo. Mesmo com a participação da sociedade prevista na sua vertente eleitoral, em Laranjal do Jari ainda não há a plena efetividade das decisões cidadãs na governabilidade para a expressar o verdadeiro controle social tão almejado pela democracia, expressa nos últimos estágios de classificação do processo participativo analisados nesse artigo.

As ações de cada cidadão refletem diretamente no funcionamento da cidade e com mais intensidade quando há articulação em prol do bem coletivo, atitude necessária para que todo o esforço empreendido na elaboração do plano tenha resultados significativos. Quando o direito à cidade é incorporado ao sentimento de pertencimento, o ator social torna-se o protagonista do desenvolvimento da cidade.

\section{REFERÊNCIAS BIBLIOGRÁFICAS}

FACCIO, Maria da Graça. Plano Diretor Participativo e a construção do espaço público nas cidades brasileiras a partir do Estatuto da Cidade: possibilidades e limites. In: RAFFAELLI, R.; LEIS, H. (Org.). Cadernos de Pesquisa Interdisciplinar em Ciências Humanas, Florianópolis, n.82, p. 2-10, 2006.

GOVERNO DO ESTADO DO AMAPÁ. Bases do desenvolvimento Sustentável, Coletânea de Textos. Macapá: Editora Supercores, 1999.

MINISTÉRIO DAS CIDADES. Plano Diretor Participativo, Guia para a elaboração pelos municípios e cidadãos. 2004

TONI, Jackson de. Planejamento Participativo: Possibilidades Metodológicas Alternativas. II Congresso Consad de Gestão Pública - Painel 14: Possibilidades para um modelo alternativo de gestão pública: em busca de um novo referencial teórico. 2009.

TOSTES, José Alberto. Planos Diretores no estado do Amapá: A experiência do município de Laranjal do Jari, uma contribuição para o desenvolvimento regional. Macapá: UNIFAP, 2009.

Planos Diretores no Estado do Amapá, Uma contribuição para o desenvolvimento regional. Macapá: J. A. Tostes, 2006. 
